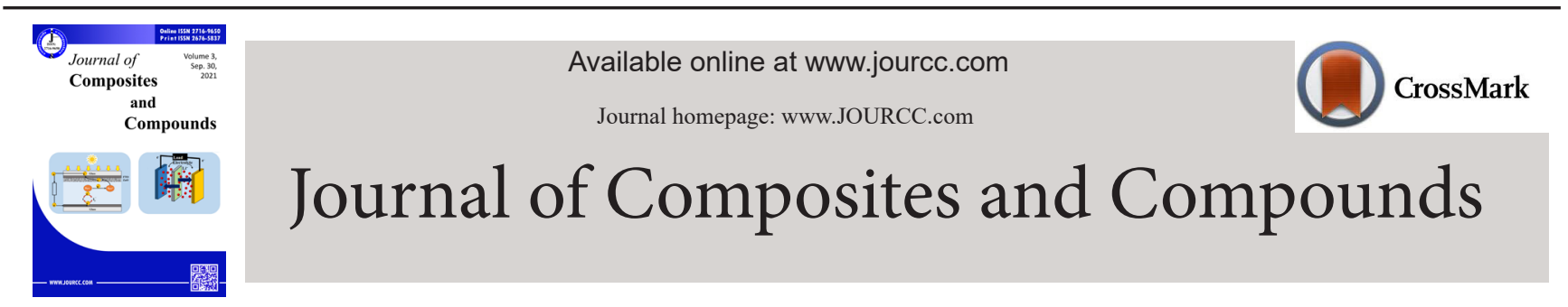

\title{
Preparation of bioactive polymer-based composite by different techniques and application in tissue engineering: A review
}

\author{
Mohammad Azad Alam a, Mohammad Hamed Asoushe ${ }^{b}$, Pouran Pourhakkak c, Lukas Gritsch d, \\ Alireza Alipour ${ }^{e}$, Somaye Mohammadi ${ }^{\text {* }}$ \\ ${ }^{a}$ Mechanical Engineering Department, Universiti Teknologi Petronas, Seri Iskandar 32610, Perak, Malaysia \\ ${ }^{b}$ School of Metallurgy and Materials Engineering, University of Tehran, Tehran, Iran \\ ${ }^{c}$ Department of Chemistry, Payame Noor University, P.O. Box 19395-1697, Tehran, Iran \\ ${ }^{d}$ Laboratoire de Physique de Clermont, Université Clermont Auvergne, 4 Avenue Blaise Pascal, 63178 Aubière (Clermont-Ferrand), France \\ ${ }^{e}$ Medical Biotechnology Research Center, Ashkezar Branch, Islamic Azad University, Yazd, Iran \\ ${ }^{f}$ Department of Organic Chemistry, University of Kashan, 87317-51167, Kashan, Iran
}

\begin{abstract}
A B S T R A C T
Tissue engineering (TE) employs biological, chemical, and engineering methods to regenerate and restore injured or lost living tissues by applying biologically activated biomaterials, cells, and molecules. The fast and convenient restoration of tissue is a great challenge, emphasizing the need to imitate tissue structure and its physicochemical, biological, and mechanical behavior to give back the desired functionality of damaged tissue. Depending on the particular tissue, numerous requirements have to be fulfilled with the help of material and scaffold design that provides a base for cell adhesion and proliferation. As a result, countless biodegradable and bioresorbable materials have been extensively examined. Composite systems combine the benefits of bioactive ceramics and polymers, which seem to be good alternatives for bone tissue engineering. This article intends to introduce bioactive polymer, tissue engineering methods, the kinds of biomaterials applied in scaffold invention, and the different approaches to producing the bioactive polymer-based composites with various structures such as porous, membrane, and 3D structure. Biomaterials and invention techniques could crucially influence the consequences of the scaffold's design architectures, cell proliferation, and mechanical behavior. Moreover, an excellent scaffold assists cell generation and the provision of cell nutrients in the human body with their particular material characteristics. (C)2021 JCC Research Group.

Peer review under responsibility of JCC Research Group
\end{abstract}

A R T I C LE IN F O R M A T I ON

\begin{tabular}{l} 
A R T I C L E I N F O R M A T I O N \\
\hline Article history: \\
Received 1 August 2021 \\
Received in revised form 11 September 2021 \\
Accepted 19 September 2021 \\
\\
\hline Keywords: \\
Scaffold \\
Tissue engineering \\
Biodegradable \\
Bioresorbable polymer-based composites \\
Activated biomaterials \\
Bioactive polymer-based composite
\end{tabular}

Table of contents

1. Introduction

2. Bioactive polymer

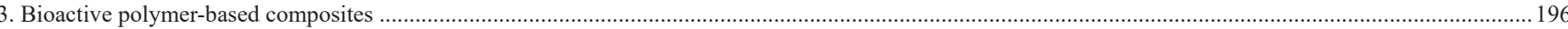

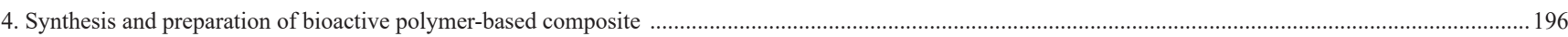

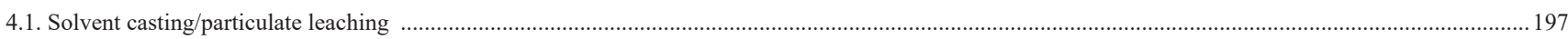

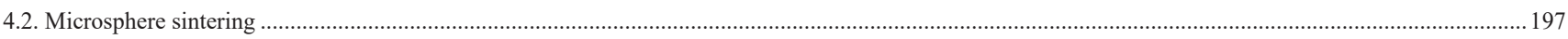

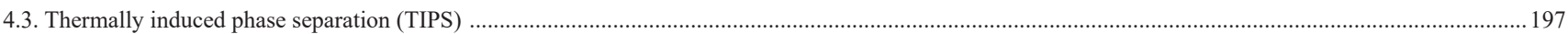

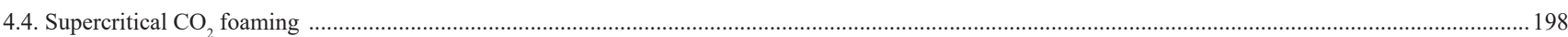

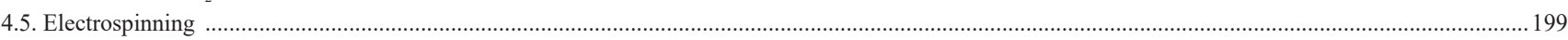

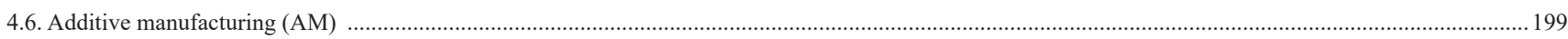

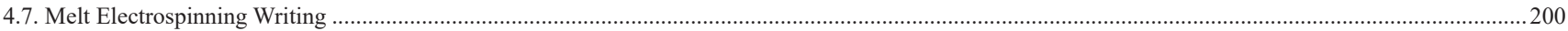

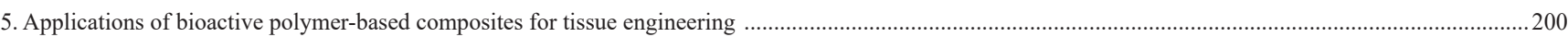

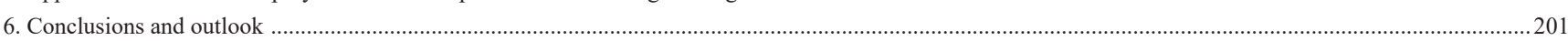

*Corresponding author: Somaye Mohammadi; E-mail: mohamadi_s65@yahoo.com

https://doi.org/10.52547/jcc.3.3.7 This is an open access article under the CC BY license (https://creativecommons.org/licenses/by/4.0) 


\section{Introduction}

The field of tissue engineering is an interdisciplinary science that needs cultured cell technology. Therefore, it uses growth factors that allow the correct and constant control of cell growth situations and materials engineering for improved biomaterials scaffolds that can imitate the structure of a process [1]. Scaffolds are a model whose key function is to work as an anchoring platform to the growth and reproduction of cells, provide rigidity to the tissue, and produce a vacant volume for vascularization [2]. Nevertheless, it must also play other roles such as releasing, transporting and storing active factors. They should be able to stimulate particular cellular responses and provide mechanical integrity for the managed region. Accordingly, characteristics such as the scaffold microstructure (interconnectivity of pores, pore size, porosity), the external geometry, and surface topographic properties (roughness or hydrophilic-hydrophobic style) significantly influence cell-scaffold reactions $[3,4]$. Moreover, the biocompatibility, degeneration, and mechanical characteristics of the scaffold have played a key role because they influence both the production of scaffold tissue in vitro and its viability and functionality once entered [5]. Scaffolds must manage the physical integrity and stability required to promote the sterilization process and be stored for a long period [6]. Recently, attempts have been carried out to estimate the influence of structural characteristics and chemicals of scaffolds on cellular manner, that is, on cell adhesion, migration, proliferation, and differentiation [7,8]. A proper raw material to achieve scaffolds by an optimal internal structure has a positive influence on the activity of cells, so it is apparent that the choice of a suitable raw material is essential for optimal cell growth. In this way, scaffolds can be made natural and synthetic, but they must exhibit their particular properties throughout the complete runtime $[9,10]$. Among the commonly used polymers, ceramic materials, polymers, and metallic materials have been significantly considered. The former is the most promising group of biomaterials used to synthesize biomedical devices [11]. This kind of material can allow scaffolds to be processed with sufficient control of the structural factors, including surface area, size and shape of pores, pore interconnectivity and porosity, and desired morphology, which are key points for cell seeding and growth, migration, tissue formation, and mass transport. The major disadvantage is the lack of hydrophilicity for cell adhesion, limiting biocompatibility [12]. As usual, synthetic polymers are classified into two types of non-biodegradable and biodegradable materials. The biodegradable ones offer the greatest utilization in tissue engineering $[13,14]$. The degeneration method of biodegradable polymers is hydrolysis by absorption of water and the enzymatic break of the polymer chain [15]. Among the various synthetic polymers, the poly- $\alpha$-hydroxy esters, including polyglycolide (PGA), polylactic acid (PLA), and polycaprolactone (PCL), have the most significant application among others [16-18]. Natural polymers (biopolymers) are extensively utilized in tissue engineering thanks to their characteristics and chemical structure, with a high affinity to water, biodegradability, biocompatibility, and Muco-adhesiveness [19]. Biocompatibility enhances the attraction of cells on the scaffolds to reconstruct damaged tissue. Nevertheless, the reduced mechanical and structural properties of these polymers restrict their widespread use. The most natural polymers are proteins and polysaccharides [20,21]. There are various fabrication methods for the preparation of polymer-based scaffolds, the ones based on 3D printing, supercritical $\mathrm{CO}_{2}$ foaming [22], electrospinning technology [23], melt electrospinning [24], thermally induced phase separation (TIPS) [25]; solvent-based methods, such as solvent casting or phase division [26], self-assembly [27], etc. However, developing technologies have recently become prevalent in this field due to the potentiality to provide highly controlled scaffolds in terms of morphological

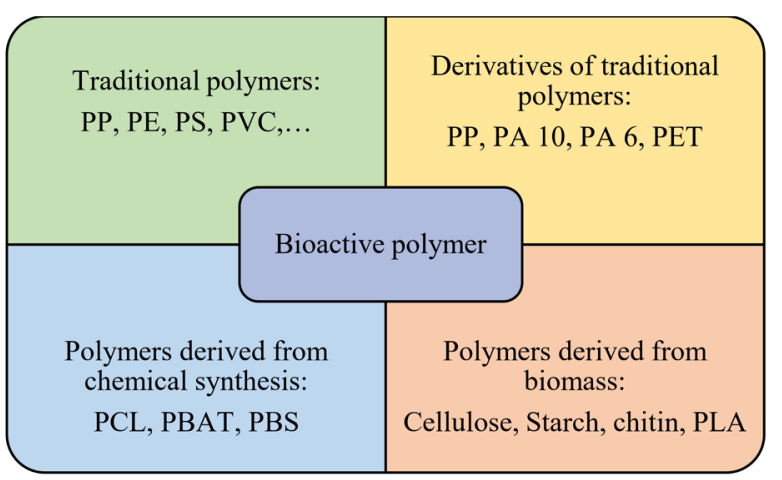

Fig. 1. Bio-based and biodegradable polymers.

and mechanical properties. Microfluidics and 3D printing methods are great examples of those emerging techniques that allow achieving a defined geometry, good interconnectivity, high control on the regularity in the pore size [28]. In this review, following past research [29-31], we have an overview of different methods for the fabrication of bioactive polymer-based composites and various structural and mechanical properties. Then applications of these materials on tissue engineering were discussed. The data were obtained in 2021, mostly from Science Direct and Google Scholar using keywords such as manufacturing technology, thermally induced phase separation, melt electrospinning, supercritical $\mathrm{CO}_{2}$ foaming electrospinning, bioactive polymer, biomaterial, and tissue engineering.

\section{Bioactive polymers}

A biomaterial was described as a material used to provide devices that can replace a section or function of an organism in a safe, physically plausible, and economical method; however, it can also be referred to as materials achieved from biological materials or biological origin $[32,33]$. Although, the acceptable explanation was supplied by William as "a non-viable material which used in a biomedical device and intended to interact with biological systems" [34]. Nowadays, biomaterials are employed for the treatment of trauma damage, aesthetics, and degenerative diseases. Also, biomaterials for treating congenital defects are becoming a requirement since human beings demand to live longer and better [35]. Currently, the average life expectancy in the world is more than 73 years; according to the United Nations Organization (UNO) data, approximately more than 950 million humans are above 60 years old, and by the end of the $21^{\text {st }}$ century, that number will be tripled $[36,37]$ The search for enhancements in life expectancy and quality has made it feasible for the modern community to observe scientific and technological advancements in several sciences during recent years[38,39]. The first advances took place at the start of the $20^{\text {th }}$ century by synthesizing the first vanadium steel alloys for fracture fixation or threads capable of being degraded and absorbed with the human body [40]. Since the 1960 s, by the implementation of statistical analysis and protocols, practical methods were employed to distinguish the structure and surfaces of materials, which led to exponential advancements in the field of biomaterials $[41,42]$. Since the 1970 s, combining medical sciences with basic sciences (chemistry, biology, and physics) and engineering has been the absolute incentive for the improvement of biomaterials. Fig. 1 indicates different types of the bioactive polymer [43].

Biomaterials are evaluated in terms of three types of properties: first, properties of biomaterials related to their response in accurate working situations; second, structure and composition; third, the behavior of biomaterials in different situations and answers to alterations in the surrounding location [44]. Biocompatibility is defined as the capacity of a 
compound to give enough response in a particular application, such as bacterial growth, resistance to blood clotting, and normal healing with an adequate response from the host (patient). Consequently, biomaterials must be effective devices that do not interfere with the metastable condition of the living body or the efficiency of the equipment in the implanted environment for an indefinite period $[40,45]$. Biomaterials have been classified in various forms based on the response of the human body or tissue to the implant. The biomaterial is recognized as toxic; if it creates fibrous tissue, the biomaterial is estimated inert if it develops a connection interface, and it is supposed to be bioactive and, ultimately, if it improves tissue replacement, the biomaterial is considered soluble [46]. At the start of using biomaterials in a different regular pathway, in the $1950 \mathrm{~s}$, the research concentrated on bio-inert materials ( $1^{\text {st }}$ generation) [47]. Over time, in the $2^{\text {nd }}$ generation, the study was directed toward the bioactivity of compounds [48]. Currently, in the $3^{\text {rd }}$ generation, the focus has been on the recovery of functional tissue and more on the human body's response rather than regaining the function with the least biological responses of the sufferer [49]. Efforts were made to prolong the life of implants during their interaction with the host tissue interface [50]. After then, the focus has been on the improvement of biodegradable materials able to be absorbed or incorporated on the host tissue, and currently, the significance of biomimetics in the $4^{\text {th }}$ generation has led to the examination of materials that actively take part in the improvement process and stimulation at the cell level [51,52].

Furthermore, the biomaterials can be whether classified according to their duration as temporary and permanent or based on the mechanical characteristics as thick tissue and soft tissue. Nevertheless, the best known and most popularly used classification is the one that classifies these by their origin as artificial or natural. The natural type of the biomaterial can be classified as ceramic, metallic, composite, and polymeric materials [53].

\section{Bioactive polymer-based composites}

Those composites that are created by the mixed of non-living and living compounds are called vital-avital composites. So, these composites are the type of synthetic scaffold that is combined with in-growing living tissue [54]. In this kind of composites, the cellular component can produce the novel tissue by the generation of the extracellular matrix and create mechanical stability and structural integrity in a short time. Overall, the composites can be considered bioresorbable and bioactive with regards to the properties of the bioactive part applied, such as systems including both bioactive silicate glasses, related calcium phosphate ceramics, and hydroxyapatite [55-57][58]. Moreover, classification can be carried out according to the architect of the scaffold as dense or porous structures. In another classification approach, the method of including the bioactive phase in the composite, such as being as an external layer, a filler, or coating, should be taken into accounts. The types of bioactive and biodegradable composites and recent references that applied them within TE are displayed in Table 1 .

Table 1.

Kinds of composite scaffolds used in tissue engineering

$$
\text { Dense (non-porous scaffold) }
$$

Porous scaffolds (foam-like structure)

\begin{tabular}{|c|c|c|c|c|c|c|c|}
\hline \multicolumn{2}{|c|}{$\begin{array}{l}\text { Bioactive component: } \\
\text { TCP, HA, and related ceramics }\end{array}$} & \multicolumn{2}{|c|}{$\begin{array}{c}\text { Bioactive component: } \\
\text { Silicate glass } \\
\left(\text { e. g. Bioglass }{ }^{\mathrm{R}}\right)\end{array}$} & \multicolumn{2}{|c|}{$\begin{array}{l}\text { Bioactive component: } \\
\mathrm{HA} \text {, TCP, and related ceramics }\end{array}$} & \multicolumn{2}{|c|}{$\begin{array}{l}\text { Bioactive component: } \\
\text { Silicate glass } \\
\left.\text { (e. g. Bioglass }{ }^{\mathrm{R}}\right)\end{array}$} \\
\hline $\begin{array}{l}\text { Bioactive } \\
\text { component: }\end{array}$ & $\begin{array}{l}\text { Bioactive } \\
\text { component: }\end{array}$ & $\begin{array}{l}\text { Bioactive } \\
\text { component: }\end{array}$ & $\begin{array}{l}\text { Bioactive } \\
\text { component: }\end{array}$ & $\begin{array}{l}\text { Bioactive } \\
\text { component: }\end{array}$ & $\begin{array}{l}\text { Bioactive } \\
\text { component: }\end{array}$ & $\begin{array}{l}\text { Bioactive } \\
\text { component: }\end{array}$ & $\begin{array}{l}\text { Bioactive } \\
\text { component: }\end{array}$ \\
\hline $\begin{array}{l}\text { Added as filler } \\
\text { Refs. }[59,60]\end{array}$ & $\begin{array}{c}\text { Added as coating } \\
\text { Ref. [61] }\end{array}$ & $\begin{array}{l}\text { Added as filler } \\
\text { Ref. [62] }\end{array}$ & $\begin{array}{c}\text { Added as coating } \\
\text { Ref. [63] }\end{array}$ & $\begin{array}{l}\text { Added as filler } \\
\text { Ref. [64] }\end{array}$ & $\begin{array}{c}\text { Added as coating } \\
\text { Ref. [65] }\end{array}$ & $\begin{array}{l}\text { Added as filler } \\
\text { Ref. [65] }\end{array}$ & $\begin{array}{c}\text { Added as coating } \\
\text { Ref. [66] }\end{array}$ \\
\hline
\end{tabular}




\subsection{Solvent casting/particulate leaching}

The solvent casting method is innovated to alleviate some of the disadvantages connected with fiber bonding formation. This technique was explained by Mikos et al. in 1996 [78]. The appropriate thermal processing can generate porous structures of synthetic biodegradable polymers by specific pore size, a ratio of surface/volume, porosity, and crystallinity for various utilization [79]. This method has been approved for PLGA and PLLA scaffolds; however, it can be used for different polymers that are dissolvable in a solvent such as methylene chloride or chloroform. The used salt particles are insoluble in chloroform solvent [80]. The solvent is evaporated by vacuum drying. As a result, the PLLA is converted to PLLA/salt films with high crystallinity. The film undergoes additional processes depending on the desired crystallinity of the final films. In this technique, the PLLA/salt films are covered with the water solvent to leach out the salt. This is used in very crystalline, salt-free PLLA film prior to drying [81]. In the other process, PLA/salt films are heated to a high temperature to ensure the complete melting of the polymer crystallites [82]. After melting, the PLLA films and dispersed salt are both annealed by freezing at a moderate and controlled speed, which provides semi-crystalline films with particular crystallinity; then are quenched to fabricate amorphous films [83]. Subsequently, the salt is leached out by being immersed in water producing salt-free PLLA membranes [84].

The solvent-casting method can be applied to fabricate the highly porous films with porosities up to $95 \%$ and an interconnected pore structure [85]. The porosity of PLLA films can be tunned by changing the volume of utilized salt to create the composite compounds. Also, the pore size of the film can be regulated separately by changing the size of the salt particles. Scaffolds with pore sizes larger than $500 \mathrm{~nm}$ have been manufactured using this method. The high surface volume/area ratios of the membranes depend on the particle size or salt weight. Moreover, according to the utilization requirements of the membrane, the crystallinity of PLLA films can be adjusted.

These properties are all acceptable characteristics of a scaffold for organ improvement. The major limitation of this approach is its capability to fabricate only thin films and membranes, and thereby 3D scaffolds cannot be produced. Membrane melt molding or lamination, nevertheless, can solve this problem [86,87]. One of the difficulties associated with the aforementioned method is that the polymer scaffolds are brittle and consequently inapplicable for soft tissue treatments. To overcome this limitation, PLGA has been combined with poly (ethylene glycol) (PEG) and shaped into flexible foams utilizing solvent-casting/particulate-leaching techniques [88]. As the amount of PEG in the mixture is raised, the flexibility of the foams is improved. Thus, thick polymer films can be designed with the capacity to be rolled into tubes without destroying the pore structure. Using this technique, foam scaffolds can be manufactured in a tabular form. These scaffolds have numerous potentials for soft tissue engineering, such as the regeneration of the esophagus and blood vessels $[89,90]$.

A concern for scaffolds prepared with PLGA or polylactic acid PLLA is the even seeding of cells, which is relevant to the hydrophobicity of the polymer. In this regard, a method has been acquired in which porous PLGA scaffolds were soaked in an aqueous suspension of a hydrophilic polymer, for example, polyvinyl alcohol (PVA) [91]. Hepatocytes seeded on the employed scaffolds were present in much greater densities than on untreated scaffolds. An alternative technique to deal with the challenge of seeding cells in PLGA or PLLA scaffolds is pre-wetting the scaffolds with ethanol solvent [78]. In this method, porous polymer scaffold films were soaked in ethanol solvent for $1 \mathrm{~h}$. The scaffolds were then submerged in water to pre-wet them. Hepatocytes and chondrocytes seeded on the pre-wetted scaffolds exhibited a stable distribution throughout the scaffolds. This method could also be probably beneficial for seeding other kinds of cells as well [92]. As a result, solvent casting by particulate leaching methods is used to generate porous structures from synthetic biodegradable polymers with particular pore sizes, ratios of surface/volume, porosity, and crystallinity for various utilizations.

\subsection{Microsphere sintering}

The development of microspheres manufactured from biopolymers, bioactive glasses, and ceramics is a continuing challenge for numerous researchers around the world. Microsphere techniques have various benefits for biomedical treatments [93]. They can be designed to have an identical shape and size, developing a larger surface area, providing adequate corrective coatings, and improving ion freedom [94]. Also, this method can help researchers create particles by hollow or porous structures and encapsulate other biomedically related materials [95]. Porous microspheres with a high surface area can be created having internal and external porosity or even a combination of them [96]. Microspheres containing porosity display larger surface area, lower mass density, cell proliferation, drug release kinetics, and drug absorption in comparison with bulk microspheres. Moreover, these microspheres can be manufactured as standalone products or collected 3D porous scaffolds [97]. According to starting materials, the porous microspheres have different properties such as pore size, level of porosity, interconnectivity, and surface area [98]. The porous microspheres by polymer-based materials have been widely investigated for drug delivery and other biological applications while carrying ingredients, such as proteins and growth factors. Whereas ceramic and glass-based microspheres have been essentially considered for bone tissue improvement, radionuclide therapy, and orthopedic and dental applications [99]. Thus, the microsphere sintering method has been applied to create the particles by hollow or porous structures and encapsulate other biomedically-related materials.

\subsection{Thermally induced phase separation (TIPS)}

In 1978, the TIPS technique was devised to manufacture microporous membranes [100]. This method involves a uniform multi-element approach (solvent, polymer, filler, drug, etc.) under determined conditions, in which a divided system comprising of two different components, a polymer-lean and a polymer-rich phase, is produced [101]. Following the evaporation of the solvent, the polymer-rich phase is turned into a porous scaffold skeleton, and the eliminated solvent provides the final porosity [102]. The mentioned technique yields polymer-based foams with a porosity of $95 \%$ [103] and pore sizes around 1 to $100 \mu \mathrm{m}$. Many innovations in this field, such as the combination of TIPS with other preparation methods including porogen leaching [104], electrospinning [105], 3D printing [106], the solvent elimination process [107], or alteration in TIPS factors [108] have been introduced. These developments have permitted scientists to fabricate a diversity of architectures and pore morphologies in nano/micrometer scales that are appropriate for particular applications. Porous scaffolds with micro/macro-porous architectures, anisotropic (oriented/aligned-pore or microtubular), isotropic (random-pore), fibrillar (micro/macro-fibrous), biphasic structures, spherulites, axialites, lamellar stacks, lamellar platelets, bilayered, and/or a combination of these constructions have lately been fabricated by TIPS techniques [109]. The wide range of 3D porous polymer-based scaffolds established by TIPS provides broad range of applications in tissue engineering for regeneration of bone, dermal, osteochondral, cardiovascular, cartilage, neural tissues, etc. The basis of TIPS method is reducing the temperature of a homogeneous multicomponent system or a homogenous polymer solution, created at high temperatures. The thermal energy reduction is utilized to trigger phase separation [110]. Whilst cooling, the system enhances unstable thermodynamically, causing distribution into two separate phases [109]. In this technique, a polymer-rich and a polymer-lean phase are presented with low and high polymer amounts, individually. The solvent that presented in the 
(a)

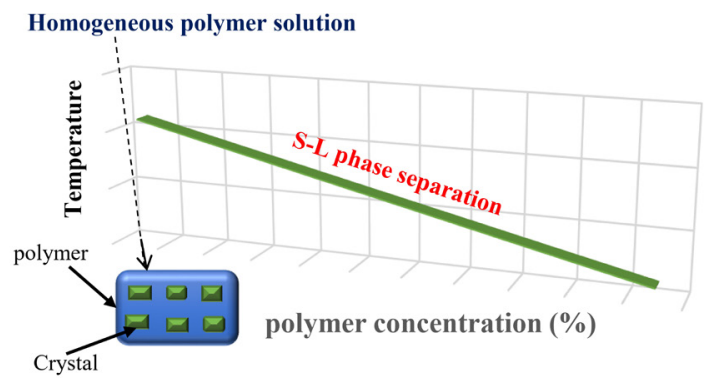

(b)

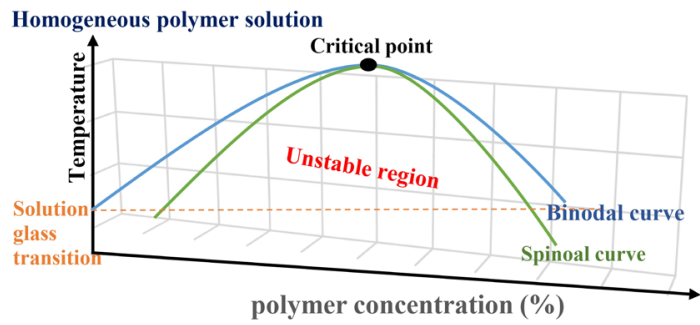

Fig. 2. TIPS method with polymer solutions via two chief mechanisms a) solid-liquid phase separation and b) liquid-liquid phase separation.

phase with lower amounts of polymer is consequently removed by evaporation, extraction or sublimation [111]. Followed by the elimination of solvent, the polymer-lean phase models of porosities and the rich phase in polymer are changed to a porous structure identified by convenient pore interconnectivity and geometry [112]. This method depends on the relationship between polymer and solvent and could be recognized by two usual mechanisms depicted in Figure 2 [113], which are called solid-liquid and liquid-liquid phase separations. The solid-liquid separation happens before solvent freezing, and the liquid-liquid separation occurs while the solvent is frozen [114]. The particular separation route could be chosen by determining the parameters of TIPS, which influence the thermodynamics of the procedure (polymer type, solvent, cooling temperature, concentration, cooling rate) [64]. Solid-liquid phase separation might occur through cooling, having convenient adaptability between the solvent and polymer (1,4-dioxane and PLA with Hansen solubility parameters (HSP)) [115], and the solvent possesses a comparatively elevated freezing point (Fig. 2a). The appearance of the solid-liquid phase-separated systems, the freezing point of the solvent, or crystallization temperature in the solution should be more significant compared to the liquid-liquid phase separation temperature. Decreasing the polymer solution's temperature leads to the crystallization of the solution, the polymer to be discharged from the crystallization exterior and the system supports solid-liquid phase division [116]. The structuration of the system is checked by the crystallization of the solvent in this method [117]. After eliminating the solvent, the achieved foam morphology is defined by the pores with the same geometry as the crystallites [118]. As an example, for the PLA solutions in the 1,4-dioxane solvent, a porous network with a mediocre pore size of about $100 \mu \mathrm{m}$ has been performed [119]. The solid-liquid phase separation of a polymer-solvent system results in a structure and pore construction of the foam, which is extensively related to the applied solvent and its crystallization temperature, polymer density, phase separation temperature, and the temperature of the system [120]. Normally, organic solvents with a low freezing point, such as 1,4-dioxane $\left(11.8^{\circ} \mathrm{C}\right)$ or benzene $\left(5.5^{\circ} \mathrm{C}\right)$ are used for the preparation of synthetic polymer networks by the solid-liquid phase separation method. With checking the cooling process, networks provid- ed by solid-liquid phase separation might have anisotropic or isotropic architectures. Networks with a random, isotropic, and pore structure are provided with transporting immediately the uniform solution to a cooling apparatus that permits solid-liquid phase separation and solvent crystallization. Certainly, by controlling the crystallization regulation and employing a uniaxial temperature in the system (via insulating the sidewalls of the mould, including polymer solution, before transporting it to the cooling apparatus) a composition of oriented pores, anisotropic, can be obtained. Liquid-liquid phase division in a polymer solution might happen throughout the cooling method while the polymer-solvent association is extremely indistinct (Fig. 2b). Schugens et al. [120] determined that combining water to a PLA/1,4-dioxane system, results in the phase division mechanism that could be repaired undercooling [121]. By combining water (a poor solvent of PLA) with the system, the cooperation between the solvent and polymer is decreased. Consequently, a liquid-liquid separation happened at temperatures which are upper than the temperature of solvent crystallization.

As a result, TIPS is a good method to manufacture microporous membranes for phase separation and purification of the liquid and gas phases.

\subsection{Supercritical $\mathrm{CO}_{2}$ Foaming}

Supercritical $\mathrm{CO}_{2}$ is one of the well-known methods to create porous scaffolds in the tissue engineering field. In this method, the porous scaffolds are generated without using dangerous organic solvent [122]. Moreover, moderately low temperature and pressure were used in $\mathrm{scCO}_{2}$ methods, respectively $31.1^{\circ} \mathrm{C}$ and $7.4 \mathrm{MPa}$. [123]. Another significant benefit of this method is to create the opportunity for accurately tuning the pore composition structure of the scaffolds and the proper choice of the processing provisions, depressurization time, gas density, solubilization pressure, and foaming temperature [124]. Numerous natural or synthetic, biodegradable, and biocompatible polymers were considered for improving bone defects. PCL is one of the most common synthetic polymers that recently corroborated as a desirable compound of bone tissue due to its ability to the in vivo and in vitro bone tissue growth for several months by achieving a nontoxic response and maintaining its mechanical properties [125]. Besides, the extrusion process is assisted by supercritical $\mathrm{CO}_{2}$. Extrusion assisted by $\mathrm{scCO}_{2}$ is an emerging technique for the microcellular foaming of polymer. Alternatively, batch foaming, which needs the production of single-phase polymer $/ \mathrm{CO}_{2}$ solution in extended period times, is tuned where the extrusion supported by supercritical fluids defeats this issue by producing fast mixing and dissolution of $\mathrm{CO}_{2}$ in the polymer melt. Because the $\mathrm{scCO}_{2}$ is solvable in several molten polymers and performances as a detachable plasticizer, its introduction into an extruder will permit a reduction of the processing temperature.

In this method, the pressure or temperature supercritical fluid is higher than the critical conditions. Supercritical fluids demonstrate particular properties such as liquid-like density and gas-like viscosity, which can be used in various applications, including particle generation methods, polymer composite processing, and microcellular foaming procedures [126]. $\mathrm{ScCO}_{2}$ is utilized in tissue engineering due to different benefits such as non-flammable, chemically inert, non-toxic, and supercritical conditions $[127,128]$. Also, it can be eliminated from the system by depressurization. The high solubility of this substance can increase the plasticizing and expansion of the material by the modification of physical and mechanical characteristics. Also, $\mathrm{scCO}_{2}$ reduces the glass transition temperature and, the viscosity of the various polymers and $\mathrm{Tg}$ without differently altering their pseudo-plastic behavior [129]. Another benefit of using $\mathrm{scCO}_{2}$ extrusion techniques is modifying the rheological characteristics of the compound inside the extruder, which also performs the role of an expansion factor [38]. The reduction of vis- 


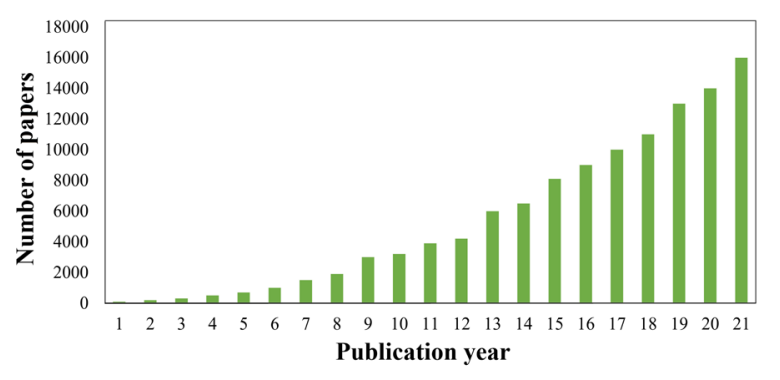

Fig. 3. The studies with electrospinning and TE in 10 years.

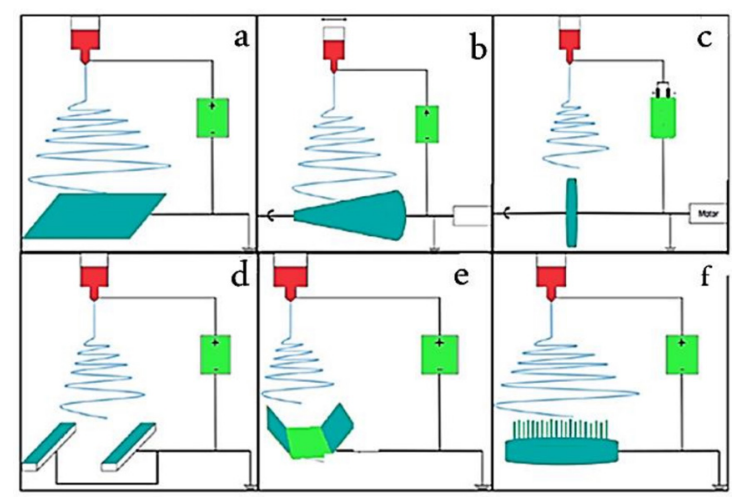

Fig. 4. Different electrospinning apparatus. a) Flat plate, b) Rotating cone, c) Rotating disc, d) Parallel stripes, e) Double inclined slopes, and f) Parallel attaining probes.

cosity will appear in the limitation of shear and mechanical stresses and provide a decrease in mixture temperatures. Consequently, the management of the molecules with insufficient thermal stability will be possible [130]. The extruders in $\mathrm{scCO}_{2}$ are classified into two various types: a) the twin-screw extruder and, b) the single-screw extruder due to the number of screws turning in the barrel [131]. The procedure of both models is similar, so, at the first step, the polymer is conveyed on the barrel, next fed and melted in the beginning part, then pressurized in the last part, and applied within the die [132]. At the end of the extruder screw can be attached to any ancillary device [133]. Also, a static mixer can be established to improve either dispersive or distributive mixing and increase the dissolution and also absorption of the $\mathrm{CO}_{2}$ in the polymer melt. Le Moigne et al. [134] attached a static mixer to the system that contains four elements. Also, in the separated research, Pilla et al. [135] and Matuana et al. connected a diffusion-enhancing device as the static mixer. In the applied research, Mihai et al. [135] attached a gear pump placed at the head of the extrusion line to maintain a high-pressure level at the collection of the extruder. Rizvi et al. [136] checked the pressure by joining a two-hole flow nozzle. As a result, the $\mathrm{scCO}_{2}$ method is the green method to create porous scaffolds in tissue engineering without the use of dangerous organic solvent.

\subsection{Electrospinning}

Electrospinning is a considerable method that has been broadly used in TE and scaffold production. According to the data obtained from Google Scholar, Scopus, Science Direct, the annual number of papers including "tissue engineering" and "electrospinning" has risen sixty-seven times in the past two decades (Fig. 3).

The electrospinning method comprises three sections: a material transfer system (regularly a thin tube including a spinneret of miniature diameter); a high voltage power system; and a fiber collection system [137]. The electrospinning method uses an elevated voltage to generate an electrically charged melt jet outside the control system or polymer solution. The jet of released polymer solution performs through elongation and instable process, and the solvent is evaporated by an elongated jet system. The jet is assembled as an interconnection of the fibers at the collector $[138,139]$ that is grounded or attached to an electrode. Due to starting material, process setup, and device combination, the electrospun fibers' diameter can be obtained from $10 \mathrm{~nm}$ to $100 \mathrm{~lm}$. Unusual melt polymers can be converted to the submicron fibers by a more powerful DC voltage in the electrospinning method [140]. Conventional electrospinning systems are shown in Fig. 4. The straightforward method which is broadly used for the creation of the membrane filtration is applying a flat plate into the collector that fibers are collected there (Fig. 4a). Different setups have a rotor that rotates the collector with a particular rotating rate to assemble aligned fibers. The concentric collector can be fabricated by a drum [141], a disc (Fig. 4c) [142], and a cone (Fig. 4b) [143]. The random-to-aligned nanofibers create a hard-soft tissue interface (Fig. 4d). The identical probes are used to obtain 3D scaffolds with fluffy structures (Fig. 4f) [144] and, likely double slopes (Figure 1e) [145] were used for aligned and random fibers, individually (Fig.4e).

The various degrees of elasticity by the electrospinning method allows fiber production from different materials that varying from natural and synthetic polymers to polymers blends which combined with new functional additives [146] including, silk, collagen, elastin, gelatin, and PGA, poly(1-lactic acid) (PLLA) and PCL [147]. PCL with crystalline nature is one of the commonly utilized biomaterials for scaffolds. electrospinning can also create porous covers as a very adaptable method for providing constant fibers of sub-micro to nano diameters [148] Moreover, the nanofiber covers regularly have extraordinary porosity, good mechanical characteristics, and a wide surface area to volume ratio [149]. The nanostructure of the covers can simulate the construction of the extracellular model (ECM) in either composition or morphology. Different models of electrospun nanofibers can be manufactured based on biomedical treatments, achieving from endocrine organs to the nervous systems, and cardiovascular applications to artificial skin [150] [151]. In the case study, Zhao et al. created 3D fibrous scaffolds using the electrospinning method by gelatin methacryloyl (GelMA) and applied them to the accelerated wound healing process [152]. Also, in the other research Sun, et al. investigated the accelerated in vivo vascularized skin flap by using the GelMA fiber. The results have rendered a more microvascular structure and higher flap endurance rate. [153]. Chen et al. applied the GelMA hydrogel fibers to create a promising survival and metabolic condition for neurons because this material can soak up water six times more than its weight. [154]. As a result, the various gegrees of elasticity by electrospinning method allows fiber production from different materials that varying from natural and synthetic polymers to polymers blends which combined with new functional additives.

\subsection{Additive Manufacturing (AM)}

Traditionally, most scaffolds were fabricated by electrospinning technique, gas forming, freeze-drying, and injection molding. Recently, additive manufacturing methods have been largely utilized in tissue engineering because of their capacity in creating complicated structures of scaffolds. This method has a low cost and is feasible to be employed in several scales [155]. Construction patterns are necessary to warrant the convenient performance of fabricated structures in vivo and in vitro analyses before human implantation [156]. Additive manufacturing techniques are now extensively utilized in TE, and many researchers have evaluated different methods to overcome the medical difficulties of transplantation [157]. Additive manufacturing techniques can control the properties of the composite, for example, porous construction, and geometry, by utilizing computer-aided design (CAD) [158]. In 1986, the first 3D printing method called SLA was formulated by Charles WHull31. AM is also capable of producing structure using liquid com- 


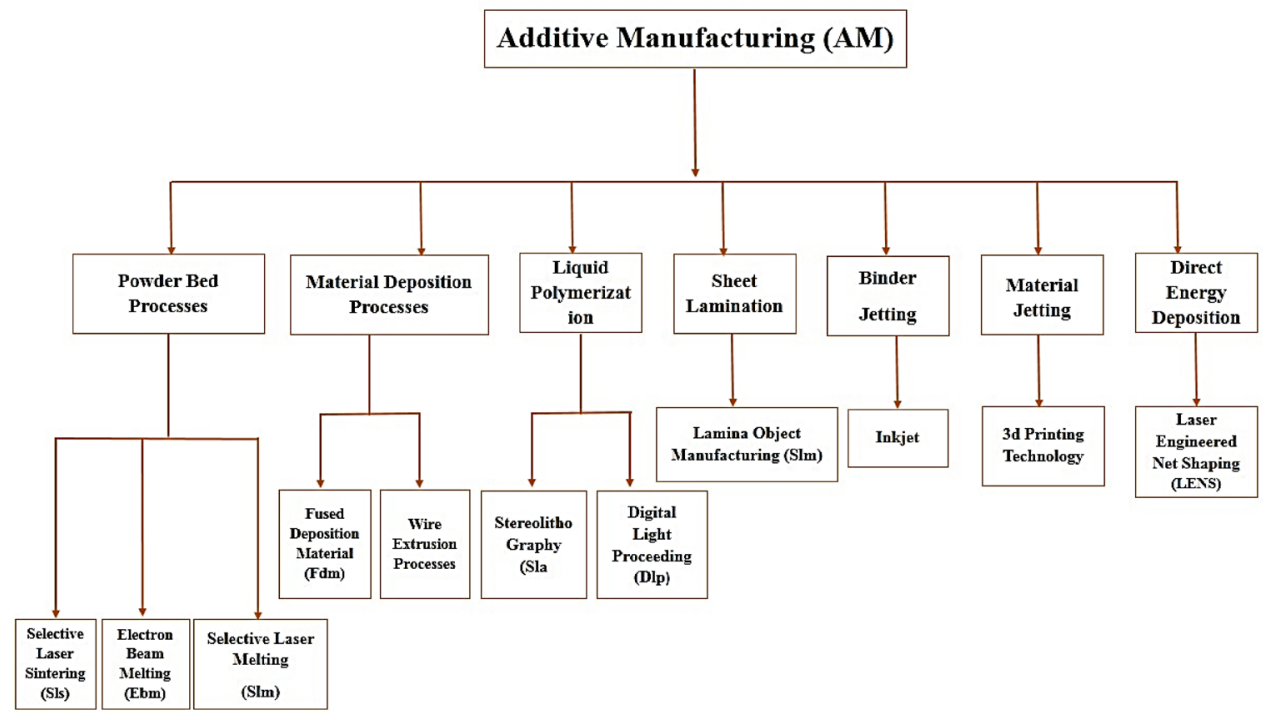

Fig. 5. The classification of AM technologies with different methods and materials.

pounds and UV light emitted in three directions to fabricate a solid 3D composition through a layer-by-layer approach [159]. Researchers have later utilized various biochemical, biomaterial, and living cell materials to produce biodegradable and biocompatible scaffolds, which satisfy the particular purposes of constructs that are recognized as 3D bioprinters. Fig. 5 displays the classification of additive manufacturing techniques [160]. Seven types of AM processes that are broadly used in TE are powder-based processes such as) SLS( $[161,162]$, the extruded-based method of thermoplastic filaments FDM [163,164], liquid-based SLA method [165], binder jetting process, sheet lamination process, laminated object fabrication (LOM) [166], material jetting method, and direct energy deposition (DED) [167-169]. As a result, the additive manufacturing (AM) techniques have the capacity to fabricate different structures in an environmentally-friendly and sustainable way by decreasing the waste of used materials.

\subsection{Melt Electrospinning Process}

The melt electrospinning (MES) process has been widely studied in recent years. This process provides fibrous structures from polymer melts or solutions and has been used for preparing scaffolds [170]. Scaffolding concepts have been largely influenced by additive production methods during the last decade. SLS fused deposition modeling (FDM), selective laser melting (SLM), hydrogel printing, and 3D printing are among the additive composition methods currently applied in the tissue engineering field [171].

The melt electrospinning is similar to the solution electrospinning method. In this method, a solution or a polymer melt is drawn from a small orifice (spinneret), connected to a high-voltage power supplier [172]. By applying a sufficiently high voltage to a liquid droplet, it becomes charged by which the surface tension counteracts due to the electrostatic repulsion. This phenomenon stretches the droplet, and a stream of liquid bursts from the surface at a critical point, providing a charged liquid jet. The formed jet dries in flight and is elongated by a whipping approach, until its deposition on the grounded collector [173]. Melt electrowriting (MEW) is used for producing nonwoven fibers with various diameters ranging from about $270 \mathrm{~nm}$ to $500 \mathrm{~mm}$ [177]. MEW provides high-resolution with the ability to fabricate micro- and nanometric fibers via a procedure similar to MES. The only difference between MEW and MES is the use of various parameters with a moving collector, which facilitates direct writing of 3D scaffolds. The MES method provides the analytical study of scaffolds by evaluating pore size and pore intercon- nectivity $[174,175]$. The parameters affecting scaffolds can be used to determine the best conditions for tissue engineering applications [176]. The 3D scaffolds are produced using a layer-by-layer process, which enhances the process of collecting data regarding scaffold models. The MES process presents significant capacity in manufacturing scaffolds with excellent reproducibility utilizing a computer-controlled system. MEW was suggested as an additive manufacturing process [177] by providing the exact arrangement of submicron and micron diameter fibers in solvent-free techniques. Recently, poly(oxazoline) and PCL have emerged for the melt electrospinning process and 3D targets with particular morphologies [178]. Vaquette et al. [187] fabricated a surface coating on the melt electrospun PCL to produce scaffolds and examined the influence of $\mathrm{CaP} 04$ protection on ectopic bone production. Different exciting suggestions were published by Park et al. [179] who explained how cellular appendage was enhanced by improving the surface area of any fiber by a formed spinneret. Mazalevska et al. [180] also produced PP and PLA tubular scaffolds with a diameter of $5 \mathrm{~mm}$. They concluded that more tests should be conducted to confirm the application of these structures in blood vessels. Consequently, it can be concluded that the melt electrospinning process is a new method in tissue engineering for clinical applications.

\section{Application of bioactive polymer-based composites for tissue engineering}

Composites are introduced as materials with more than two components. Combining polymers with other materials provides different characteristics, including biocompatibility, surface characteristics, and mechanical strength, which make it possible to fabricate compounds with unique biological activity and mechanical properties [181]. The composites prepared from polymers are usually applied in military, aerospace, and automobile industries as well as a different scientific fields for drug delivery, tissue engineering, regenerative medicine, wound dressings, surgical operations, and dental resin composites [182,183]. A large number of studies in this field comprise different methods to fabricate various types of biomaterials from polymer-based composites. Bioactive polymer-based composites fabricated by microsphere sintering, additive manufacturing, and electrospinning methods present promising characteristics for biomedical applications, including wound healing and tissue engineering [184]. Moreover, they can be used in medical imaging to determine cancer disease or assist precise cancer treatment [185]. Also, 
the composites prepared with the supercritical $\mathrm{CO}_{2}$ foaming method can develop the technology of maxillofacial surgery using bone tissue engineering and promoting periodontics and implantology, producing new substitute bone grafts [186]. The composites fabricated by the melt electrospinning method can be used in stereolithography, FDM, selective laser sintering, hydrogel printing, and 3D printing [164]. Also, the composites fabricated by the thermally induced phase separation (TIPS) method can be utilized for phase separation, purification of the liquid, and gas phase [119].

Salamanca et al. reported the production of collagenated porcine grafts and concluded that collagenated porcine graft stimulated osteoblast differentiation in vitro and illustrated guided bone reconstruction in vivo. PLLA is one of the important biodegradable polymers that is generally utilized in orthopedic devices [187]. Poly-L-lactide is one of the important biodegradable polymers that is generally utilized in orthopedic devices [188]. Although PLLA shows unique biocompatibility, its inadequate mechanical strength confines its application in load-bearing regions. Therefore, for resolving this problem, the improvement of bone tissue by adding PLLA was investigated [189]. Leu et al. [190] combined PLLA and tricalcium silicate to produce a novel membrane and utilized it to limit leakage of polymethyl-methacrylate (PMMA) bone cement through kyphoplasty modification. They emphasized that the antidegradation properties and mechanical characteristics of the new composite could be improved without changing the cytocompatibility, providing a possible antileakage membrane for the kyphoplasty classification of osteoporosis-related spine breaks. Soft tissue reconstruction is a different paramount tissue engineering issue. Huang et al. [191] developed hydrogels of thermosensitive chitosan-gelatin-glycerol phosphate to produce a collagenase carrier for tendon bone. Following experiments with an organism model, they recommended this new composite as a possible compound to support tendon-to-bone remedy.

\section{Conclusions and outlook}

In this research, the result of 189 studies was analyzed and classified according to structural properties, used biomaterials, and types of different methods for TE applications. Different methods have been applied for the fabrication of composites in TE. In this paper, several methods were reviewed, including (I) casting/particulate solvent method, a thermal processing method, for generating porous composites, (II) microsphere sintering method, applied to create the hollow or porous structures, (III) thermally induced phase separation method, mainly used to manufacture microporous membranes for phase separation, (IV) supercritical $\mathrm{CO}_{2}\left(\mathrm{scCO}_{2}\right)$ method to create porous scaffolds in green condition, (V) electrospinning method for creating fiber composites, (VI) additive manufacturing for fabricating structures by the green method, and (VII) melt electrospinning process as a new method.

These composites have been applied for 3D bioprinting of bone, implantation, organs regeneration, drug delivery, and scaffold fabrication. Scaffolds with excellent characteristics can be fabricated by novel techniques using printing machines and changing machine parameters. The typical biomaterials that could be applied in TE techniques are still being investigated. In this review, different polymers, including PCL and PLA in combination with other compounds for the preparation of bioactive polymers, were discussed. Biomaterials have been conveniently produced for TE using these methods. It is presumed that the composite of various materials can improve the mechanical properties and material characteristics of scaffolds.

The result of the review paper can be used by the researcher for further investigation in different fields of TE techniques, fabrication methods, and biomaterials utilized in biological cell generation as well as tissue engineering development. Biomaterials and processing methods can significantly affect the final properties such as design architectures, cell proliferation, and mechanical behavior of the scaffolds used in tissue engineering. Recent advances in bioactive polymer-based composites have provided significant advantages for preparing polymer-based compounds with appropriate characteristics for tissue engineering. However, more studies should be performed on the newly-emerged processing techniques of bioactive polymer-based composites to guaranty their safe and effective application in the human body. The melt electrospinning process is one of the promising methods for fabricating polymer-based constructions, which has to be investigated in more detail before being employed for tissue engineering applications.

\section{REFERENCES}

[1] M.S. Chapekar, Tissue engineering: challenges and opportunities, J. Biomed. Mater. Res. An Off. J. Soc. Biomater. Japanese Soc. Biomater. Aust. Soc. Biomater. Korean Soc. Biomater. 53 (2000) 617-620.

[2] S. Yin, W. Zhang, Z. Zhang, X. Jiang, Recent Advances in Scaffold Design and Material for Vascularized Tissue-Engineered Bone Regeneration, Adv. Healthc. Mater. 8 (2019) 1801433

[3] L.G. Griffith, G. Naughton, Tissue engineering--current challenges and expanding opportunities, Science (80-. ). 295 (2002) 1009-1014.

[4] The Binary Genetic Algorithm, in Practical Genetic Algorithms. (2003) 27-50. [5] D. Nesic, R. Whiteside, M. Brittberg, D. Wendt, I. Martin, P. Mainil-Varlet, Cartilage tissue engineering for degenerative joint disease, Adv. Drug Deliv. Rev. 58 (2006) 300-322.

[6] A.A. Vu, D.A. Burke, A. Bandyopadhyay, S. Bose, Effects of surface area and topography on 3D printed tricalcium phosphate scaffolds for bone grafting applications, Addit. Manuf. 39 (2021) 101870

[7] J. Sun, Q. Zheng, Y. Wu, Y. Liu, X. Guo, W. Wu, Biocompatibility of KLD-12 peptide hydrogel as a scaffold in tissue engineering of intervertebral discs in rabbits, J. Huazhong Univ. Sci. Technol. [Medical Sci. 30 (2010) 173-177.

[8] A. Mishra, Y. Loo, R. Deng, Y.J. Chuah, H.T. Hee, J.Y. Ying, C.A.E. Hauser, Ultrasmall natural peptides self-assemble to strong temperature-resistant helical fibers in scaffolds suitable for tissue engineering, Nano Today. 6 (2011) 232-239. [9] B.-S. Kim, D.J. Mooney, Development of biocompatible synthetic extracellular matrices for tissue engineering, Trends Biotechnol. 16 (1998) 224-230.

[10] B. Guo, P.X. Ma, Synthetic biodegradable functional polymers for tissue engineering: a brief review, Sci. China Chem. 57 (2014) 490-500.

[11] A.B. Pratt, F.E. Weber, H.G. Schmoekel, R. Müller, J.A. Hubbell, Synthetic extracellular matrices for in situ tissue engineering, Biotechnol. Bioeng. 86 (2004) $27-36$.

[12] J.D. Kretlow, A.G. Mikos, Mineralization of synthetic polymer scaffolds for bone tissue engineering, Tissue Eng. 13 (2007) 927-938.

[13] R.S. Bhatnagar, J.J. Qian, A. Wedrychowska, M. Sadeghi, Y.M. Wu, N. Smith, Design of biomimetic habitats for tissue engineering with P-15, a synthetic peptide analogue of collagen, Tissue Eng. 5 (1999) 53-65.

[14] M.P. Lutolf, J.A. Hubbell, Synthetic biomaterials as instructive extracellular microenvironments for morphogenesis in tissue engineering, Nat. Biotechnol. 23 (2005) 47-55.

[15] K.P. Andriano, Y. Tabata, Y. Ikada, J. Heller, In vitro and in vivo comparison of bulk and surface hydrolysis in absorbable polymer scaffolds for tissue engineering, J. Biomed. Mater. Res. An Off. J. Soc. Biomater. Japanese Soc. Biomater. Aust. Soc. Biomater. Korean Soc. Biomater. 48 (1999) 602-612.

[16] A. Kyzioł, K. Kyzioł, Surface functionalization with biopolymers via plasma-assisted surface grafting and plasma-induced graft polymerization — materials for biomedical applications, in: Biopolym. Grafting, Elsevier, (2018) 115-151.

[17] T. Tariverdian, F. Sefat, M. Gelinsky, M. Mozafari, Scaffold for bone tissue engineering, in: Handb. Tissue Eng. Scaffolds Vol. One, Elsevier, (2019) 189-209. [18] E.I. Paşcu, Bioactive and biodegradable scaffolds for hard tissue engineering, (2009).

[19] J.M. Dang, K.W. Leong, Natural polymers for gene delivery and tissue engineering, Adv. Drug Deliv. Rev. 58 (2006) 487-499.

[20] S.A. Sell, P.S. Wolfe, K. Garg, J.M. McCool, I.A. Rodriguez, G.L. Bowlin, The use of natural polymers in tissue engineering: a focus on electrospun extracellular matrix analogues, Polymers (Basel). 2 (2010) 522-553.

[21] M. Swetha, K. Sahithi, A. Moorthi, N. Srinivasan, K. Ramasamy, N. Selvamurugan, Biocomposites containing natural polymers and hydroxyapatite for bone tissue engineering, Int. J. Biol. Macromol. 47 (2010) 1-4.

[22] M. Laurenti, V. Cauda, Biodegradable polymer nanocomposites for tissue engineering: Synthetic strategies and related applications, in: Mater. Biomed. Eng., 
Elsevier, (2019) 157-198.

[23] X. Wang, B. Ding, B. Li, Biomimetic electrospun nanofibrous structures for tissue engineering, Mater. Today. 16 (2013) 229-241.

[24] R. Sahay, P.S. Kumar, R. Sridhar, J. Sundaramurthy, J. Venugopal, S.G. Mhaisalkar, S. Ramakrishna, Electrospun composite nanofibers and their multifaceted applications, J. Mater. Chem. 22 (2012) 12953-12971.

[25] A.E. Erickson, J. Sun, S.K.L. Levengood, S. Swanson, F.-C. Chang, C.T. Tsao, M. Zhang, Chitosan-based composite bilayer scaffold as an in vitro osteochondral defect regeneration model, Biomed. Microdevices. 21 (2019) 1-16.

[26] M. Choudhury, S. Mohanty, S. Nayak, Effect of different solvents in solvent casting of porous PLA scaffolds-In biomedical and tissue engineering applications, J. Biomater. Tissue Eng. 5 (2015) 1-9.

[27] B. Zavan, R. Cortivo, G. Abatangelo, Hydrogels and tissue engineering, in: Hydrogels, Springer, (2009) 1-8.

[28] D.J. Richards, Y. Tan, J. Jia, H. Yao, Y. Mei, 3D printing for tissue engineering, Isr. J. Chem. 53 (2013) 805-814.

[29] S. Mohammadi, H. Naeimi, A synergetic effect of sonication with yolk-shell nanocatalyst for green synthesis of spirooxindoles, Green Chem. Lett. Rev. 14 (2021) 344-356.

[30] H. Naeimi, S. Mohammadi, Synthesis of $1 \mathrm{H}-$-Isochromenes, $4 \mathrm{H}-\mathrm{Chromenes}$ and Orthoaminocarbonitrile Tetrahydronaphthalenes by $\mathrm{CaMgFe}_{2} \mathrm{O}_{4}$ Base Nanocatalyst, ChemistrySelect. 5 (2020) 2627-2633.

[31] S. Mohammadi, H. Naeimi, A bifunctional Yolk-Shell nanocatalyst with Lewis and organic functional base for the synthesis of spirooxindoles, Appl. Catal. A Gen. 602 (2020) 117720.

[32] A. Muxika, A. Etxabide, J. Uranga, P. Guerrero, K. De La Caba, Chitosan as a bioactive polymer: Processing, properties and applications, Int. J. Biol. Macromol. 105 (2017) 1358-1368.

[33] A. Michiardi, G. Hélary, P.-C. Nguyen, L.J. Gamble, F. Anagnostou, D.G. Castner, V. Migonney, Bioactive polymer grafting onto titanium alloy surfaces, Acta Biomater. 6 (2010) 667-675.

[34] D.F. Williams, On the nature of biomaterials, Biomaterials. 30 (2009) 58975909.

[35] J. Liao, X. Guo, K.J. Grande-Allen, F.K. Kasper, A.G. Mikos, Bioactive polymer/extracellular matrix scaffolds fabricated with a flow perfusion bioreactor for cartilage tissue engineering, Biomaterials. 31 (2010) 8911-8920.

[36] R. Gentsch, F. Pippig, S. Schmidt, P. Cernoch, J. Polleux, H.G. Börner, Single-step electrospinning to bioactive polymer nanofibers, Macromolecules. 44 (2011) 453-461

[37] I. Sukmana, Bioactive polymer scaffold for fabrication of vascularized engineering tissue, J. Artif. Organs. 15 (2012) 215-224.

[38] H. Nargesi khoramabadi, M. Arefian, M. Hojjati, I. Tajzad, A. Mokhtarzade, M. Mazhar, A. Jamavari, A review of Polyvinyl alcohol/Carboxymethyl cellulose (PVA/CMC) composites for various applications, J. Compos. Compd. 2 (2020) 69-76.

[39] J. Daraei, Production and characterization of PCL (Polycaprolactone) coated $\mathrm{TCP} /$ nanoBG composite scaffolds by sponge foam method for orthopedic applications, J. Compos. Compd. 2 (2020) 44-49.

[40] W. Cao, L.L. Hench, Bioactive materials, Ceram. Int. 22 (1996) 493-507.

[41] W. He, R. Benson, Polymeric biomaterials, in: Appl. Plast. Eng. Handb., Elsevier, (2017) 145-164.

[42] M. Chi, M. Qi, P. Wang, M.D. Weir, M.A. Melo, X. Sun, B. Dong, C. Li, J. $\mathrm{Wu}$, L. Wang, Novel bioactive and therapeutic dental polymeric materials to inhibit periodontal pathogens and biofilms, Int. J. Mol. Sci. 20 (2019) 278.

[43] A. Abuchenari, K. Hardani, S. Abazari, F. Naghdi, M.A. Keleshteri, A. Jamavari, A.M. Chahardehi, Clay-reinforced nanocomposites for the slow release of chemical fertilizers and water retention, J. Compos. Compd. 2 (2020) 85-91. [44] J.S. Patel, S. V Patel, N.P. Talpada, H.A. Patel, Bioactive polymers: Synthesis, release study and antimicrobial properties of polymer bound Ampicillin, Die Angew. Makromol. Chemie. 271 (1999) 24-27.

[45] C.G. Gebelein, C.E. Carraher, Biotechnology and bioactive polymers, Springer, 1994.

[46] K. Varaprasad, G.M. Raghavendra, T. Jayaramudu, M.M. Yallapu, R. Sadiku, A mini review on hydrogels classification and recent developments in miscellaneous applications, Mater. Sci. Eng. C. 79 (2017) 958-971.

[47] P. Parida, A. Behera, S.C. Mishra, Classification of Biomaterials used in Medicine, (2012).

[48] M.E.S. Hassan, J. Bai, D.-Q. Dou, Biopolymers; definition, classification and applications, Egypt. J. Chem. 62 (2019) 1725-1737.

[49] K. Zhang, Q. Van Le, Bioactive glass coated zirconia for dental implants: a review, J. Compos. Compd. 2 (2020) 10-17.

[50] M.D. Steven, J.H. Hotchkiss, Non-migratory bioactive polymers (NMBP) in food packaging, Woodhead Publishing Ltd, Cambridge, UK, 2003.

[51] Y. Ikada, H. Tsuji, Biodegradable polyesters for medical and ecological applications, Macromol. Rapid Commun. 21 (2000) 117-132.

[52] M. Kurakula, N.R. Naveen, Prospection of recent chitosan biomedical trends: Evidence from patent analysis (2009-2020), Int. J. Biol. Macromol. (2020).

[53] G. Radenković, D. Petković, Metallic biomaterials, in: Biomater. Clin. Pract., Springer, (2018) 183-224.

[54] A.R. Boccaccini, J.J. Blaker, Bioactive composite materials for tissue engineering scaffolds, Expert Rev. Med. Devices. 2 (2005) 303-317.

[55] M.-H. Thibault, C. Comeau, G. Vienneau, J. Robichaud, D. Brown, R. Bruening, L.J. Martin, Y. Djaoued, Assessing the potential of boronic acid/chitosan/ bioglass composite materials for tissue engineering applications, Mater. Sci. Eng. C. 110 (2020) 110674

[56] Q. Chen, J.A. Roether, A.R. Boccaccini, Tissue engineering scaffolds from bioactive glass and composite materials, Top. Tissue Eng. 4 (2008) 1-27.

[57] R.A. MacDonald, B.F. Laurenzi, G. Viswanathan, P.M. Ajayan, J.P. Stegemann, Collagen-carbon nanotube composite materials as scaffolds in tissue engineering, J. Biomed. Mater. Res. Part A An Off. J. Soc. Biomater. Japanese Soc. Biomater. Aust. Soc. Biomater. Korean Soc. Biomater. 74 (2005) 489-496.

[58] M.R. Ghahramani, A.A. Garibov, T.N. Agayev, M.A. Mohammadi, A novel way to production yttrium glass microspheres for medical applications, Glas. Phys. Chem. 40 (2014) 283-287.

[59] S.M. Kenny, M. Buggy, Bone cements and fillers: a review, J. Mater. Sci. Mater. Med. 14 (2003) 923-938.

[60] M. Kobayashi, T. Nakamura, Y. Okada, A. Fukumoto, T. Furukawa, H. Kato, T. Kokubo, T. Kikutani, Bioactive bone cement: Comparison of apatite and wollastonite containing glass-ceramic, hydroxyapatite, and $\beta$-tricalcium phosphate fillers on bone-bonding strength, J. Biomed. Mater. Res. An Off. J. Soc. Biomater. Japanese Soc. Biomater. Aust. Soc. Biomater. 42 (1998) 223-237.

[61] F. Hajiali, S. Tajbakhsh, A. Shojaei, Fabrication and properties of polycaprolactone composites containing calcium phosphate-based ceramics and bioactive glasses in bone tissue engineering: a review, Polym. Rev. 58 (2018) 164-207.

[62] A. Hoppe, N.S. Güldal, A.R. Boccaccini, A review of the biological response to ionic dissolution products from bioactive glasses and glass-ceramics, Biomaterials. 32 (2011) 2757-2774.

[63] T.J. Brunner, W.J. Stark, A.R. Boccaccini, Nanoscale bioactive silicate glasses in biomedical applications, Pref. XV List Contrib. XIX. (2009).

[64] L.L. HENCH, A.J. SALINAS, Bioactivity of silicate glasses containing phosphate, Phosphorus Res. Bull. 6 (1996) 51-58.

[65] K. Fujikura, N. Karpukhina, T. Kasuga, D.S. Brauer, R.G. Hill, R. V Law, Influence of strontium substitution on structure and crystallisation of Bioglass $\mathbb{B}$ 45S5, J. Mater. Chem. 22 (2012) 7395-7402.

[66] K. Rezwan, Q.Z. Chen, J.J. Blaker, A.R. Boccaccini, Biodegradable and bioactive porous polymer/inorganic composite scaffolds for bone tissue engineering, Biomaterials. 27 (2006) 3413-3431.

[67] W. Florkiewicz, D. Słota, A. Placek, K. Pluta, B. Tyliszczak, T.E.L. Douglas, A. Sobczak-Kupiec, Synthesis and characterization of polymer-based coatings modified with bioactive ceramic and bovine serum albumin, J. Funct. Biomater. $12(2021) 21$.

[68] J.K.Y. Lee, N. Chen, S. Peng, L. Li, L. Tian, N. Thakor, S. Ramakrishna, Polymer-based composites by electrospinning: Preparation \& functionalization with nanocarbons, Prog. Polym. Sci. 86 (2018) 40-84.

[69] Z. Guo, A.A. Poot, D.W. Grijpma, Advanced polymer-based composites and structures for biomedical applications, Eur. Polym. J. 149 (2021) 110388.

[70] N. Cioffi, L. Torsi, N. Ditaranto, G. Tantillo, L. Ghibelli, L. Sabbatini, T. Bleve-Zacheo, M. D’Alessio, P.G. Zambonin, E. Traversa, Copper nanoparticle/ polymer composites with antifungal and bacteriostatic properties, Chem. Mater. 17 (2005) 5255-5262.

[71] G. Joshi, V. Sharma, R. Saxena, K.S. Yadav, Polylactic coglycolic acid (PLGA)-based green materials for drug delivery, in: Appl. Adv. Green Mater., Elsevier, (2021) 425-440.

[72] G.S. Mann, L.P. Singh, P. Kumar, S. Singh, C. Prakash, On briefing the surface modifications of polylactic acid: A scope for betterment of biomedical structures, J. Thermoplast. Compos. Mater. (2019) 0892705719856052.

[73] H. Zhou, J.G. Lawrence, S.B. Bhaduri, Fabrication aspects of PLA-CaP/PLGA-CaP composites for orthopedic applications: a review, Acta Biomater. 8 (2012) 1999-2016.

[74] P.S.P. Poh, M.A. Woodruff, E. García-Gareta, Polymer-based composites for musculoskeletal regenerative medicine, in: Biomater. Organ Tissue Regen., Elsevier, (2020) 33-82.

[75] C.R. Holkar, A.J. Jadhav, S.E. Karekar, A.B. Pandit, D.V. Pinjari, Recent developments in synthesis of nanomaterials utilized in polymer based composites for 
food packaging applications, (n.d.).

[76] A. Jha, A. Kumar, Biobased technologies for the efficient extraction of biopolymers from waste biomass, Bioprocess Biosyst. Eng. 42 (2019) 1893-1901.

[77] Y. Liu, P. Yin, J. Chen, B. Cui, C. Zhang, F. Wu, Conducting polymer-based composite materials for therapeutic implantations: from advanced drug delivery system to minimally invasive electronics, Int. J. Polym. Sci. 2020 (2020).

[78] L. Lu, A.G. Mikos, The importance of new processing techniques in tissue engineering, Mrs Bull. 21 (1996) 28-32.

[79] A. Prasad, M.R. Sankar, V. Katiyar, State of art on solvent casting particulate leaching method for orthopedic scaffoldsfabrication, Mater. Today Proc. 4 (2017) 898-907.

[80] W.L. Murphy, R.G. Dennis, J.L. Kileny, D.J. Mooney, Salt fusion: an approach to improve pore interconnectivity within tissue engineering scaffolds, Tissue Eng. 8 (2002) 43-52.

[81] R. Huang, X. Zhu, H. Tu, A. Wan, The crystallization behavior of porous poly (lactic acid) prepared by modified solvent casting/particulate leaching technique for potential use of tissue engineering scaffold, Mater. Lett. 136 (2014) 126-129.

[82] X. Zhu, T. Zhong, R. Huang, A. Wan, Preparation of hydrophilic poly (lactic acid) tissue engineering scaffold via (PLA)-(PLA-b-PEG)-(PEG) solution casting and thermal-induced surface structural transformation, J. Biomater. Sci. Polym. Ed. 26 (2015) 1286-1296.

[83] A. Moghanian, A. Ghorbanoghli, M. Kazem-Rostami, A. Pazhouheshgar, E. Salari, M. Saghafi Yazdi, T. Alimardani, H. Jahani, F. Sharifian Jazi, M. Tahriri, Novel antibacterial $\mathrm{Cu} / \mathrm{Mg}$-substituted 58S-bioglass: Synthesis, characterization and investigation of in vitro bioactivity, Int. J. Appl. Glas. Sci. 11 (2020) 685-698. [84] P. Abasian, M. Radmansouri, M.H. Jouybari, M.V. Ghasemi, A. Mohammadi, M. Irani, F.S. Jazi, Incorporation of magnetic NaX zeolite/DOX into the PLA/ chitosan nanofibers for sustained release of doxorubicin against carcinoma cells death in vitro, Int. J. Biol. Macromol. 121 (2019) 398-406.

[85] S. Lee, B. Kim, S.H. Kim, S.W. Kang, Y.H. Kim, Thermally produced biodegradable scaffolds for cartilage tissue engineering, Macromol. Biosci. 4 (2004) 802-810.

[86] L. Lu, S.J. Peter, M.D. Lyman, H.-L. Lai, S.M. Leite, J.A. Tamada, J.P. Vacanti, R. Langer, A.G. Mikos, In vitro degradation of porous poly (L-lactic acid) foams, Biomaterials. 21 (2000) 1595-1605

[87] J.M. Taboas, R.D. Maddox, P.H. Krebsbach, S.J. Hollister, Indirect solid free form fabrication of local and global porous, biomimetic and composite $3 \mathrm{D}$ polymer-ceramic scaffolds, Biomaterials. 24 (2003) 181-194.

[88] R.C. Thomson, M.C. Wake, M.J. Yaszemski, A.G. Mikos, Biodegradable polymer scaffolds to regenerate organs, Biopolym. Ii. (1995) 245-274.

[89] N. Thadavirul, P. Pavasant, P. Supaphol, Development of polycaprolactone porous scaffolds by combining solvent casting, particulate leaching, and polymer leaching techniques for bone tissue engineering, J. Biomed. Mater. Res. Part A. 102 (2014) 3379-3392.

[90] R.C. Thomson, A.K. Shung, M.J. Yaszemski, A.G. Mikos, Polymer scaffold processing, Princ. Tissue Eng. 2 (2000) 251-262.

[91] K.H. Bouhadir, D.J. Mooney, In vitro and In vivo Models for the Reconstruction of Intercellular Signaling a, (1998).

[92] S.L. Ishaug-Riley, L.E. Okun, G. Prado, M.A. Applegate, A. Ratcliffe, Human articular chondrocyte adhesion and proliferation on synthetic biodegradable polymer films, Biomaterials. 20 (1999) 2245-2256.

[93] M. Singh, B. Sandhu, A. Scurto, C. Berkland, M.S. Detamore, Microsphere-based scaffolds for cartilage tissue engineering: Using subcritical $\mathrm{CO}_{2}$ as a sintering agent, Acta Biomater. 6 (2010) 137-143.

[94] B. Duan, M. Wang, Encapsulation and release of biomolecules from Ca-P/ PHBV nanocomposite microspheres and three-dimensional scaffolds fabricated by selective laser sintering, Polym. Degrad. Stab. 95 (2010) 1655-1664.

[95] L.S. Fard, N.S. Peighambardoust, H.W. Jang, A. Dehghan, N.N.K. Saligheh, M. Iranpour, M.I. Rajabi, The rechargeable aluminum-ion battery with different composite cathodes: A review, J. Compos. Compd. 2 (2020) 138-146.

[96] A.A. Chaudhari, K. Vig, D.R. Baganizi, R. Sahu, S. Dixit, V. Dennis, S.R. Singh, S.R. Pillai, Future prospects for scaffolding methods and biomaterials in skin tissue engineering: a review, Int. J. Mol. Sci. 17 (2016) 1974.

[97] T. Weigel, G. Schinkel, A. Lendlein, Design and preparation of polymeric scaffolds for tissue engineering, Expert Rev. Med. Devices. 3 (2006) 835-851.

[98] L.S. Farda, N.S. Peighambardoustb, H.W. Jangc, A. Dehghand, N.N.K. Salighehe, M. Iranpourf, M.I. Rajabig, Journal of Composites and Compounds, (2020).

[99] K.M.Z. Hossain, U. Patel, I. Ahmed, Development of microspheres for biomedical applications: a review, Prog. Biomater. 4 (2015) 1-19. https://doi. org/10.1007/s40204-014-0033-8.

[100] I.J. Roh, S. Ramaswamy, W.B. Krantz, A.R. Greenberg, Poly (ethylene chlo- rotrifluoroethylene) membrane formation via thermally induced phase separation (TIPS), J. Memb. Sci. 362 (2010) 211-220.

[101] J.T. Jung, J.F. Kim, H.H. Wang, E. Di Nicolo, E. Drioli, Y.M. Lee, Understanding the non-solvent induced phase separation (NIPS) effect during the fabrication of microporous PVDF membranes via thermally induced phase separation (TIPS), J. Memb. Sci. 514 (2016) 250-263.

[102] H. Matsuyama, S. Berghmans, D.R. Lloyd, Formation of anisotropic membranes via thermally induced phase separation, Polymer (Guildf). 40 (1999) 2289-2301.

[103] Y.S. Nam, T.G. Park, Porous biodegradable polymeric scaffolds prepared by thermally induced phase separation, J. Biomed. Mater. Res. An Off. J. Soc. Biomater. Japanese Soc. Biomater. Aust. Soc. Biomater. Korean Soc. Biomater. 47 (1999) 8-17.

[104] H. Matsuyama, M. Yuasa, Y. Kitamura, M. Teramoto, D.R. Lloyd, Structure control of anisotropic and asymmetric polypropylene membrane prepared by thermally induced phase separation, J. Memb. Sci. 179 (2000) 91-100.

[105] D.R. Lloyd, S.S. Kim, K.E. Kinzer, Microporous membrane formation via thermally-induced phase separation. II. Liquid — liquid phase separation, J. Memb. Sci. 64 (1991) 1-11.

[106] R. Zeinali, L.J. Del Valle, J. Torras, J. Puiggalí, Recent progress on biodegradable tissue engineering scaffolds prepared by thermally-induced phase separation (Tips), Int. J. Mol. Sci. 22 (2021) 3504.

[107] Y.S. Nam, T.G. Park, Biodegradable polymeric microcellular foams by modified thermally induced phase separation method, Biomaterials. 20 (1999) 1783-1790.

[108] G. Chen, Y. Lin, X. Wang, Formation of microporous membrane of isotactic polypropylene in dibutyl phthalate-soybean oil via thermally induced phase separation, J. Appl. Polym. Sci. 105 (2007) 2000-2007.

[109] S.S. Kim, D.R. Lloyd, Thermodynamics of polymer/diluent systems for thermally induced phase separation: 2. Solid-liquid phase separation systems, Polymer (Guildf). 33 (1992) 1036-1046.

[110] I.L. TUTOR, PLLA-BASED SCAFFOLDS FOR OSTEOCHONDRAL TISSUE REGENERATION VIA THERMALLY INDUCED PHASE SEPARATION TECHNIQUE, (n.d.)

[111] X. Li, X. Lu, Morphology of polyvinylidene fluoride and its blend in thermally induced phase separation process, J. Appl. Polym. Sci. 101 (2006) 2944-2952. [112] Z. Cui, N.T. Hassankiadeh, S.Y. Lee, J.M. Lee, K.T. Woo, A. Sanguineti, V. Arcella, Y.M. Lee, E. Drioli, Poly (vinylidene fluoride) membrane preparation with an environmental diluent via thermally induced phase separation, J. Memb. Sci. 444 (2013) 223-236.

[113] G.A. Mannella, G. Conoscenti, F.C. Pavia, V. La Carrubba, V. Brucato, Preparation of polymeric foams with a pore size gradient via Thermally Induced Phase Separation (TIPS), Mater. Lett. 160 (2015) 31-33.

[114] F.C. Pavia, V. La Carrubba, S. Piccarolo, V.M.B. Brucato, Polymeric scaffolds prepared via thermally induced phase separation: tuning of structure and morphology, J. Biomed. Mater. Res. Part A An Off. J. Soc. Biomater. Japanese Soc. Biomater. Aust. Soc. Biomater. Korean Soc. Biomater. 86 (2008) 459-466.

[115] R. Akbarzadeh, A. Yousefi, Effects of processing parameters in thermally induced phase separation technique on porous architecture of scaffolds for bone tissue engineering, J. Biomed. Mater. Res. Part B Appl. Biomater. 102 (2014) 1304-1315

[116] J.T. Jung, H.H. Wang, J.F. Kim, J. Lee, J.S. Kim, E. Drioli, Y.M. Lee, Tailoring nonsolvent-thermally induced phase separation (N-TIPS) effect using triple spinneret to fabricate high performance PVDF hollow fiber membranes, J. Memb. Sci. 559 (2018) 117-126.

[117] D.R. Lloyd, K.E. Kinzer, H.S. Tseng, Microporous membrane formation via thermally induced phase separation. I. Solid-liquid phase separation, J. Memb. Sci. 52 (1990) 239-261.

[118] D. Li, W.B. Krantz, A.R. Greenberg, R.L. Sani, Membrane formation via thermally induced phase separation (TIPS): Model development and validation, J. Memb. Sci. 279 (2006) 50-60.

[119] H. Khalilpour, P. Shafiee, A. Darbandi, M. Yusuf, S. Mahmoudi, Z. Moazzami Goudarzi, S. Mirzamohammadi, Application of Polyoxometalate-based composites for sensor systems: A review, J. Compos. Compd. 3 (2021) 129-139. https://doi.org/10.52547/jcc.3.2.6.

[120] S. Ramaswamy, A.R. Greenberg, W.B. Krantz, Fabrication of poly (ECTFE) membranes via thermally induced phase separation, J. Memb. Sci. 210 (2002) 175-180.

[121] F. Sharifianjazi, A.H. Pakseresht, M.S. Asl, A. Esmaeilkhanian, H.W. Jang, M. Shokouhimehr, Hydroxyapatite consolidated by zirconia: applications for dental implant, J. Compos. Compd. 2 (2020) 26-34.

[122] M.Z. Moghadam, S. Hassanajili, F. Esmaeilzadeh, M. Ayatollahi, M. Ah- 
madi, Formation of porous HPCL/LPCL/HA scaffolds with supercritical $\mathrm{CO}_{2}$ gas foaming method, J. Mech. Behav. Biomed. Mater. 69 (2017) 115-127.

[123] L.J. White, V. Hutter, H. Tai, S.M. Howdle, K.M. Shakesheff, The effect of processing variables on morphological and mechanical properties of supercritical $\mathrm{CO}_{2}$ foamed scaffolds for tissue engineering, Acta Biomater. 8 (2012) 61-71.

[124] A. Salerno, S. Zeppetelli, E. Di Maio, S. Iannace, P.A. Netti, Design of bimodal PCL and PCL-HA nanocomposite scaffolds by two step depressurization during solid-state supercritical $\mathrm{CO}_{2}$ foaming, Macromol. Rapid Commun. 32 (2011) 1150-1156.

[125] C.-X. Chen, Q.-Q. Liu, X. Xin, Y.-X. Guan, S.-J. Yao, Pore formation of poly ( $\varepsilon$-caprolactone) scaffolds with melting point reduction in supercritical $\mathrm{CO}_{2}$ foaming, J. Supercrit. Fluids. 117 (2016) 279-288.

[126] A. Salerno, S. Zeppetelli, E. Di Maio, S. Iannace, P.A. Netti, Novel 3D porous multi-phase composite scaffolds based on PCL, thermoplastic zein and ha prepared via supercritical $\mathrm{CO}_{2}$ foaming for bone regeneration, Compos. Sci. Technol. 70 (2010) 1838-1846.

[127] M. Alizadeh, F. Sharifianjazi, E. Haghshenasjazi, M. Aghakhani, L. Rajabi, Production of nanosized boron oxide powder by high-energy ball milling, Synth. React. Inorganic, Met. Nano-Metal Chem. 45 (2015) 11-14.

[128] F.S. Jazi, N. Parvin, M. Tahriri, M. Alizadeh, S. Abedini, M. Alizadeh, The relationship between the synthesis and morphology of $\mathrm{SnO}_{2}-\mathrm{Ag}_{2} \mathrm{O}$ nanocomposite, Synth. React. Inorganic, Met. Nano-Metal Chem. 44 (2014) 759-764.

[129] R. Jiang, T. Liu, Z. Xu, C.B. Park, L. Zhao, Improving the continuous microcellular extrusion foaming ability with supercritical $\mathrm{CO}_{2}$ of thermoplastic polyether ester elastomer through in-situ fibrillation of polytetrafluoroethylene, Polymers (Basel). 11 (2019) 1983.

[130] K. Wang, Y. Pang, F. Wu, W. Zhai, W. Zheng, Cell nucleation in dominating formation of bimodal cell structure in polypropylene/polystyrene blend foams prepared via continuous extrusion with supercritical $\mathrm{CO}_{2}$, J. Supercrit. Fluids. 110 (2016) 65-74.

[131] Y. Jia, S. Bai, C.B. Park, Q. Wang, Effect of boric acid on the foaming properties and cell structure of poly (vinyl alcohol) foam prepared by supercritical- $\mathrm{CO}_{2}$ thermoplastic extrusion foaming, Ind. Eng. Chem. Res. 56 (2017) 6655-6663.

[132] L.M. Matuana, C.A. Diaz, Study of cell nucleation in microcellular poly (lactic acid) foamed with supercritical $\mathrm{CO}_{2}$ through a continuous-extrusion process, Ind. Eng. Chem. Res. 49 (2010) 2186-2193.

[133] H.-Y. Mi, X. Jing, Y. Liu, L. Li, H. Li, X.-F. Peng, H. Zhou, Highly durable superhydrophobic polymer foams fabricated by extrusion and supercritical $\mathrm{CO}_{2}$ foaming for selective oil absorption, ACS Appl. Mater. Interfaces. 11 (2019) 7479-7487.

[134] N. Le Moigne, M. Sauceau, M. Benyakhlef, R. Jemai, J.-C. Bénézet, E. Rodier, J.-M. Lopez-Cuesta, J. Fages, Foaming of poly (3-hydroxybutyrate-co-3-hydroxyvalerate)/organo-clays nano-biocomposites by a continuous supercritical $\mathrm{CO}_{2}$ assisted extrusion process, Eur. Polym. J. 61 (2014) 157-171.

$[135]$ M. Chauvet, M. Sauceau, J. Fages, Extrusion assisted by supercritical $\mathrm{CO}_{2}: \mathrm{A}$ review on its application to biopolymers, J. Supercrit. Fluids. 120 (2017) 408-420. [136] R. Kapoor, A. Jash, S.S.H. Rizvi, Shelf-life extension of Paneer by a sequential supercritical- $\mathrm{CO}_{2}$-based process, LWT. 135 (2021) 110060.

[137] A. Nouri, B. Faraji Dizaji, N. Kianinejad, A. Jafari Rad, S. Rahimi, M. Irani, F. Sharifian Jazi, Simultaneous linear release of folic acid and doxorubicin from ethyl cellulose/chitosan $/ \mathrm{g}-\mathrm{C}_{3} \mathrm{~N}_{4} / \mathrm{MoS}$, core-shell nanofibers and its anticancer properties, J. Biomed. Mater. Res. Part A. 109 (2021) 903-914.

[138] S. Khorshidi, A. Solouk, H. Mirzadeh, S. Mazinani, J.M. Lagaron, S. Sharifi, S. Ramakrishna, A review of key challenges of electrospun scaffolds for tissue-engineering applications, J. Tissue Eng. Regen. Med. 10 (2016) 715-738.

[139] A.P. Kishan, E.M. Cosgriff-Hernandez, Recent advancements in electrospinning design for tissue engineering applications: A review, J. Biomed. Mater. Res. Part A. 105 (2017) 2892-2905.

[140] D.R. Nisbet, J.S. Forsythe, W. Shen, D.I. Finkelstein, M.K. Horne, A review of the cellular response on electrospun nanofibers for tissue engineering, J. Biomater. Appl. 24 (2009) 7-29.

[141] H. Pan, L. Li, L. Hu, X. Cui, Continuous aligned polymer fibers produced by a modified electrospinning method, Polymer (Guildf). 47 (2006) 4901-4904.

[142] H. Li, X. Chen, W. Lu, J. Wang, Y. Xu, Y. Guo, Application of Electrospinning in Antibacterial Field, Nanomaterials. 11 (2021) 1822.

[143] X. Wang, K. Zhang, M. Zhu, H. Yu, Z. Zhou, Y. Chen, B.S. Hsiao, Continuous polymer nanofiber yarns prepared by self-bundling electrospinning method, Polymer (Guildf). 49 (2008) 2755-2761.

[144] Y.-H. Wu, D.-G. Yu, H.-P. Li, X.-Y. Wu, X.-Y. Li, Medicated structural PVP/ PEG composites fabricated using coaxial electrospinning, E-Polymers. 17 (2017) 39-44.

[145] G. Sargazi, D. Afzali, A. Mostafavi, H. Kazemian, A novel composite de- rived from a metal organic framework immobilized within electrospun nanofibrous polymers: An efficient methane adsorbent, Appl. Organomet. Chem. 34 (2020) e5448.

[146] W.E. Teo, S. Ramakrishna, A review on electrospinning design and nanofibre assemblies, Nanotechnology. 17 (2006) R89.

[147] H.Y. Li, M.M. Bubakir, T. Xia, X.F. Zhong, Y.M. Ding, W.M. Yang, Mass production of ultra-fine fibre by melt electrospinning method using umbellate spinneret, Mater. Res. Innov. 18 (2014) S4-921.

[148] F.S. Jazi, N. Parvin, M. Rabiei, M. Tahriri, Z.M. Shabestari, A.R. Azadmehr, Effect of the synthesis route on the grain size and morphology of $\mathrm{ZnO} / \mathrm{Ag}$ nanocomposite, J. Ceram. Process. Res. 13 (2012) 523-526.

[149] M.J. Mochane, T.S. Motsoeneng, E.R. Sadiku, T.C. Mokhena, J.S. Sefadi, Morphology and properties of electrospun PCL and its composites for medical applications: A mini review, Appl. Sci. 9 (2019) 2205.

[150] F.A. Sheikh, H.W. Ju, J.M. Lee, B.M. Moon, H.J. Park, O.J. Lee, J.-H. Kim, D.-K. Kim, C.H. Park, 3D electrospun silk fibroin nanofibers for fabrication of artificial skin, Nanomedicine Nanotechnology, Biol. Med. 11 (2015) 681-691.

[151] A. Shokati, A.N. Moghadasi, M. Nikbakht, M.A. Sahraian, S.A. Mousavi, J. $\mathrm{Ai}, \mathrm{A}$ focus on allogeneic mesenchymal stromal cells as a versatile therapeutic tool for treating multiple sclerosis, Stem Cell Res. Ther. 12 (2021) 1-13.

[152] Y. Piao, H. You, T. Xu, H.-P. Bei, I.Z. Piwko, Y.Y. Kwan, X. Zhao, Biomedical applications of gelatin methacryloyl hydrogels, Eng. Regen. 2 (2021) 47-56.

[153] X. Sun, Q. Lang, H. Zhang, L. Cheng, Y. Zhang, G. Pan, X. Zhao, H. Yang, Y. Zhang, H.A. Santos, Electrospun photocrosslinkable hydrogel fibrous scaffolds for rapid in vivo vascularized skin flap regeneration, Adv. Funct. Mater. 27 (2017) 1604617.

[154] G.Y. Xu, L.N. Chen, Z.Y. Xin, Y.X. Liu, T.C. Li, L.P. An, G.X. Yuan, Y. Sheng, P.G. Du, H.Y. Li, Review on clinical application of deproteinized calf blood extractive, in: Appl. Mech. Mater., Trans Tech Publ, (2014) 1617-1621.

[155] Y. Zamani, H. Ghazanfari, G. Erabi, A. Moghanian, B. Fakić, S.M. Hosseini, B.P. Mahammod, A review of additive manufacturing of Mg-based alloys and composite implants, J. Compos. Compd. 3 (2021) 71-83.

[156] K. Gunawardana, Introduction of Advanced Manufacturing Technology: a literature review, Sabaragamuwa Univ. J. 6 (2006) 116-134.

[157] J. Savolainen, M. Collan, How additive manufacturing technology changes business models?-review of literature, Addit. Manuf. 32 (2020) 101070.

[158] F.T.S. Chan, M.H. Chan, H. Lau, R.W.L. Ip, Investment appraisal techniques for advanced manufacturing technology (AMT): a literature review, Integr. Manuf. Syst. (2001).

[159] M. Vaezi, H. Seitz, S. Yang, A review on 3D micro-additive manufacturing technologies, Int. J. Adv. Manuf. Technol. 67 (2013) 1721-1754.

[160] C.-H. Chen, J.M.-J. Liu, C.-K. Chua, S.-M. Chou, V.B.-H. Shyu, J.-P. Chen, Cartilage tissue engineering with silk fibroin scaffolds fabricated by indirect additive manufacturing technology, Materials (Basel). 7 (2014) 2104-2119.

[161] H. Canziani, S. Chiera, T. Schuffenhauer, S. Kopp, F. Metzger, A. Bück, M. Schmidt, N. Vogel, Bottom-Up Design of Composite Supraparticles for PowderBased Additive Manufacturing, Small. 16 (2020) 2002076,

[162] S. Dolnicar, A. Chapple, A.J. “ANGIOSTRONGYLUS-V.I.N.D.I.N.W.. V.R. 120. 1. (1987): 424-424.

[163] L. Zhao, X. Wang, H. Xiong, K. Zhou, D. Zhang, Optimized preceramic polymer for 3D structured ceramics via fused deposition modeling, J. Eur. Ceram. Soc. 41 (2021) 5066-5074.

[164] K. Ryan, Additive Manufacturing of Graphene Nanoplatelets and Hexagonal Boron Nitride Composites Via Stereolithography, (2020).

[165] S. Jang, S. Park, C. Bae, Development of ceramic additive manufacturing: process and materials technology, Biomed. Eng. Lett. (2020) 1-11.

[166] L.J. Tan, W. Zhu, K. Zhou, Recent progress on polymer materials for additive manufacturing, Adv. Funct. Mater. 30 (2020) 2003062.

[167] M. Warschauer, Researching technology in TESOL: Determinist, instrumental, and critical approaches, TESOL Q. 32 (1998) 757-761.

[168] J. Zhou, J. Lin, X. Huang, Y. Zhou, Y. Chen, J. Xia, H. Wang, Y. Xie, H. Yu, J. Lei, A library of atomically thin metal chalcogenides, Nature. 556 (2018) 355-359. [169] T. Jungst, W. Smolan, K. Schacht, T. Scheibel, J. Groll, Strategies and molecular design criteria for 3D printable hydrogels, Chem. Rev. 116 (2016) 1496-1539. [170] U. Jammalamadaka, K. Tappa, Recent advances in biomaterials for 3D printing and tissue engineering, J. Funct. Biomater. 9 (2018) 22.

[171] A. Bruyas, F. Lou, A.M. Stahl, M. Gardner, W. Maloney, S. Goodman, Y.P. Yang, Systematic characterization of 3D-printed PCL/ $/$-TCP scaffolds for biomedical devices and bone tissue engineering: Influence of composition and porosity, J. Mater. Res. 33 (2018) 1948-1959.

[172] M. Vaezi, S. Chianrabutra, B. Mellor, S. Yang, Multiple material additive manufacturing-Part 1: a review: this review paper covers a decade of research on 
multiple material additive manufacturing technologies which can produce complex geometry parts with different materials, Virtual Phys. Prototyp. 8 (2013) 19-50.

[173] H. Li, B.-J. Li, Z.-J. Shi, Challenge and progress: palladium-catalyzed sp 3 C-H activation, Catal. Sci. Technol. 1 (2011) 191-206.

[174] Functionalized $\mathrm{NiFe}_{2} \mathrm{O}_{4}$ /mesopore silica anchored to guanidine nanocomposite as a catalyst for synthesis of $4 \mathrm{H}$-chromenes under ultrasonic irradiation, $\mathrm{J}$. Compos. Compd. 3 (2021). https://doi.org/10.52547/jcc.3.2.1.

[175] S. Nasibi, K. Alimohammadi, L. Bazli, S. Eskandarinezhad, A. Mohammadi, N. Sheysi, TZNT alloy for surgical implant applications: A systematic review, J. Compos. Compd. 2 (2020) 62-68.

[176] S.H. Park, T.G. Kim, H.C. Kim, D.-Y. Yang, T.G. Park, Development of dual scale scaffolds via direct polymer melt deposition and electrospinning for applications in tissue regeneration, Acta Biomater. 4 (2008) 1198-1207.

[177] S. Naghieh, M.R.K. Ravari, M. Badrossamay, E. Foroozmehr, M. Kadkhodaei, Numerical investigation of the mechanical properties of the additive manufactured bone scaffolds fabricated by FDM: the effect of layer penetration and post-heating, J. Mech. Behav. Biomed. Mater. 59 (2016) 241-250.

[178] M.L. Muerza-Cascante, D. Haylock, D.W. Hutmacher, P.D. Dalton, Melt electrospinning and its technologization in tissue engineering, Tissue Eng. Part B Rev. 21 (2015) 187-202.

[179] T.G. Kim, D.S. Lee, T.G. Park, Controlled protein release from electrospun biodegradable fiber mesh composed of poly ( $\varepsilon$-caprolactone) and poly (ethylene oxide), Int. J. Pharm. 338 (2007) 276-283.

[180] O. Mazalevska, M.H. Struszczyk, I. Krucinska, Design of vascular prostheses by melt electrospinning — structural characterizations, J. Appl. Polym. Sci. 129 (2013) 779-792

[181] V. Balouchi, F.S. Jazi, A. Saidi, Developing (W, Ti) C-(Ni, Co) nanocomposite by SHS method, J. Ceram. Process. Res. 16 (2015) 605-608.

[182] A. Deraine, M.T. Rebelo Calejo, R. Agniel, M. Kellomäki, E. Pauthe, M. Boissière, J. Massera, Polymer-Based Honeycomb Films on Bioactive Glass: To- ward a Biphasic Material for Bone Tissue Engineering Applications, ACS Appl. Mater. Interfaces. (2021)

[183] M. Wang, Composite scaffolds for bone tissue engineering, Am. J. Biochem. Biotechnol. (2006).

[184] I.O. Oladele, T.F. Omotosho, A.A. Adediran, Polymer-based composites: an indispensable material for present and future applications, Int. J. Polym. Sci. 2020 (2020).

[185] K.T. Arul, E. Manikandan, R. Ladchumananandasivam, Polymer-based calcium phosphate scaffolds for tissue engineering applications, in: Nanoarchitectonics Biomed., Elsevier, (2019) 585-618.

[186] L. Bazli, M. Yusuf, A. Farahani, M. Kiamarzi, Z. Seyedhosseini, M. Nezhadmansari, M. Aliasghari, M. Iranpoor, Application of composite conducting polymers for improving the corrosion behavior of various substrates: A Review, J. Compos. Compd. 2 (2020) 228-240.

[187] S. V Dorozhkin, Calcium orthophosphate-based bioceramics, Materials (Basel). 6 (2013) 3840-3942.

[188] W. Zakrzewski, M. Dobrzynski, Z. Rybak, M. Szymonowicz, R.J. Wiglusz, Selected nanomaterials' application enhanced with the use of stem cells in acceleration of alveolar bone regeneration during augmentation process, Nanomaterials. $10(2020) 1216$

[189] Y. Liu, J. Lim, S.-H. Teoh, Development of clinically relevant scaffolds for vascularised bone tissue engineering, Biotechnol. Adv. 31 (2013) 688-705.

[190] P. Bartolo, J.-P. Kruth, J. Silva, G. Levy, A. Malshe, K. Rajurkar, M. Mitsuishi, J. Ciurana, M. Leu, Biomedical production of implants by additive electro-chemical and physical processes, CIRP Ann. 61 (2012) 635-655.

[191] Y.-M. Huang, Y.-C. Lin, C.-Y. Chen, Y.-Y. Hsieh, C.-K. Liaw, S.-W. Huang, Y.-H. Tsuang, C.-H. Chen, F.-H. Lin, Thermosensitive chitosan-gelatin-glycerol phosphate hydrogels as collagenase carrier for tendon-bone healing in a rabbit model, Polymers (Basel). 12 (2020) 436. 